\title{
TIINEYSAJAN PITUUS VIIKIN OPETUS- JA KOETILAN AYRSHIREKARJASSA
}

\author{
Aarne Mäkelä ja Rajja Oittila \\ Kotieläintieteellinen laitos, Helsingin yliopisto
}

Saapunut 10.5.1955

\section{Aikaisempaa tietoa tiineysajan pituudesta naudalla}

Tiineysajan pituus on lajinomainen ominaisuus. Se vaihtelee eri eläinlajeilla huomattavasti, kun sensijaan vaihtelu saman lajin piirissä on suhteellisen vähäinen. Tiineysajan pituus on yleensä sitä suurempi, mitä kookkaampi laji on.

Naudan tiineysajan pituus on yleensä vähän yli 9 kuukautta. Se vaihtelee eri roduilla kuitenkin jonkin verran, joten keskimääräisiä tiineysajan pituuksia tarkemmin ilmoitettaessa on syytä samalla mainita rotu. Brakel et al. (3, pp. 179-191) ovat Ohion valtiossa Yhdysvalloissa laskeneet melko suureen aineistoon perustuen viiden karjarodun tiineysajan pituuden keskiarvot ja päätyneet tällöin seuraaviin tuloksiin: Ayrshire 278.16 \pm 0.23 , Ruskea Sveitsiläinen (Brown Swiss) $288.36 \pm$ 0.61 , Guernsay $282.67 \pm 0.28$, Holstein-Friesiläinen $278.57 \pm 0.28$ ja Jersey $277.87 \pm 0.38$ vuorokautta. Axelssox (1, p. 215) on todennut eteläruotsalaisen Alankomaan karjan tiineysajan keskipituudeksi sonnivasikkatapauksissa $279.6 \pm$ 0.144 vuorokautta ja lehmävasikkatapauksissa $278.37 \pm 0.129$ vuorokautta ja Ruotsin punakirjavan rodun tiineysajan keskipituudeksi vastaavasti $285.85 \pm 0.480$ ja $284.62 \pm 0.447$ vuorokautta.

Pehu-Lehtonen (13, pp. 38-69) on tarkastuskirjanpidosta kerännyt 5696 tiineyskertaa käsittävän aineiston. Tiedot koskevat Ayrshire-, länsisuomalaisia ja sekarotuisia karjoja. Lisäksi on erikseen käsitelty Jokioisten kartanoitten Ayrshirekarjoista saadut 2492 tiineystapausta. Tiineysaikojen keskipituudet nähdään taulukosta 1 .

Wilhelm (ref. Sabatini, 15, p. 37) on tutkinut rodun varhais- tai myöhäiskypsyyden vaikutusta tiineysaikaan. Kohtalaisen suureen aineistoon perustuen hän totesi, että varhaiskypsässä Hollantilaisessa rodussa tiineysajan pituus on 
Taulukko 1. Tiineysaikojen keskipituus eri karjaroduissa Suomessa.

\begin{tabular}{lrr}
\hline Eläinryhmä & $\begin{array}{c}\text { Tapausten } \\
\text { luku }\end{array}$ & $\begin{array}{c}\text { Tiineysaika } \\
\text { vrk }\end{array}$ \\
\hline Ayrshirekarjat & 2754 & $280.7 \pm 0.14$ \\
Jokioisten Ayrshirekarjat & 2492 & 278.8 \\
Länsisuomalaiset karjat & 1961 & $279.5 \pm 0.16$ \\
Sekarotuiset karjat & 981 & $281.4 \pm 0.24$ \\
\hline
\end{tabular}

keskimäärin 277.3 ja myöhäiskypsässä Lavanttaler-rodussa keskimäärin 290.7 vuorokautta.

Edellisestä ilmenee, että tiineysajan pituus eri roduilla jonkin verran vaihtelee. Myös saman rodun piirissä ilmenee melkoista vaihtelua. Niinpä Knotrin (10, p. 87-97) tutkimuksessa tiineysaika vaihteli $275-285$ vuorokauteen noin 75 prosentilla lehmistä Holstein-Friesiläisessä karjassa. PeHU-Lehtosen (1. c.) tutkimuksessa tiineysaika vaihteli 270 -290 vuorokauteen 88.12 prosentilla lehmistä kotimaisissa karjoissa. Äärimmäisyystapauksissa tiineysajan pituuden vaihtelu voi luonnollisesti olla huomattavasti suurempikin. Niinpä KNotrin (1. c.) aineistossa $1.7 \%$ lehmistä poiki alle 270 ja $2.7 \%$ yli 290 tiineysvuorokauden kuluttua. BRAKELin et al. (3, p. 179) aineiston 1062 tiineystapauksesta 15 tiineyttä kesti alle 241 päivää ja 32 yli 301 päivää. Copelandin (5, p. 366) Jersey-karjaa koskevassa aineistossa lyhin tiineysaika oli 228 vrk ja pisin 312 vrk. BECKER (ref. SpAnN, 17, p. 79) mainitsee eräistä lehmistä, joiden tiineysaika oli 336 - 392 vrk. Vasikat painoivat $70-75$ $\mathrm{kg}$, eräs jopa $100 \mathrm{~kg}$. Lehmät oli astutettu samalla sonnilla. Rotua ei ole ilmoitettu. Äärimmäiset tiineysajat Penu-Lehtosen (1. c.) kotimaisia karjoja koskevassa aineistossa olivat 240 ja 321 vrk. Ilmeisestikin edellä mainitut lyhyet tiineysajat eivät kysymyksessä olevien tutkijain käsityksen mukaan ole olleet sairauden tai tapaturman aiheuttamia.

Tiineysajan pituuden muuntelu johtuu ainakin osittain perinnöllisistä tekijöistä. Tämä on ilmeistä, kun on kysymys rotujen välisestä muuntelusta. FrasErin (7, pp. 158-159) mukaan eräitten Holstein-rodun lehmien pitempi tiineysaika (335 vrk) näytti olevan täysin vallitseva Kreolen-rodun lyhyempään tiineysaikaan (252 vrk) nähden.

Myös samassa rodussa saattaa lehmän ja sikiön perintöasulla olla vaikutusta tiineysajan pituuteen. Niinpä WERnER (18, p. 436) mainitsee eräästä Canaveserotuisesta sonnista, jota ei voitu enää käyttää, koska sillä astutetut lehmät poikivat säännöllisesti vasta 10 ja 11 kuukautta kestäneen tiineysajan jälkeen. SAmJATIN (16, p. 314) mainitsee eräästä Kirgiisiläisrotuun kuuluvasta sonnista, jonka jälkeläisvasikoiden sikiökausi oli huomattavasti lyhyempi kuin yleensä tällä rodulla. Vasikat olivat syntyessään myös melkoisesti kevyempiä kuin rodun vasikat keskimäärin. Edelleen BRAKEL et al. (1. c.) ovat todenneet eri sonnien jälkeläisten sikiökausien 
pituuksissa merkittäviä eroja. Sonnin vaikutus selitetään sikiön välityksellä tapahtuvana hormonaalisena vaikutuksena emäeläimeen.

Sikäli kun tiineysajan pituus on riippuvainen perinnöllisistä tekijöistä, on ilmeisesti kysymys lehmän ja sikiön hormonaalisesta konstitutiosta t.s. hormoonirauhasten toiminnasta ja niiden keskeisistä vuorovaikutuksista.

Perinnöllisiin tekijöihin liittyy myös vasikan sukupuoli. Sonnivasikoiden sikiökausi on Johanssonin (9, pp. 567-568), Copelandin (1. c.), Knottin (l. c.) ja BRAKELin et al. (l. c.) mukaan noin yksi vuorokausi pitempi kuin lehmävasikoilla. Pehu-Lehtonen (l. c.) on saanut vastaavaksi erotukseksi länsisuomalaisissa karjoissa 1.41 ja Ayrshire-karjoissa 1.22 vrk. Vasikan sukupuoli vaikuttaa ilmeisesti sikiön hormonaalisen konstitution välityksellä.

Kaksosvasikoitten sikiökauden on yleisesti havaittu olevan lyhyemmän kuin yksittäisvasikoitten. JoHANssonin (l. c.) mukaan yksittäisvasikoitten sikiökausi oli keskimäärin $5.2 \pm 0.518$ ja KNotTin (l. c.) mukaan 4.4 vrk pitempi kuin kaksosilla. KNotтin mukaan sonnivasikat näyttävät pidentävän tiineysaikaa kaksostapauksissa. Puschin (14, p. 179) mukaan kaksosten lyhyempi sikiökausi johtuu siitä, että ne voimakkaammin ärsyttävät ja rasittavat kohtua.

Lehmän iällä on jonkinverran vaikutusta tiineysajan pituuteen. JoHANssovin (l. c.), KnotTin (l. c.) ja BRAKelin et al. (l. c.) mukaan ensikantoisten tiineysaika on 1.5-2 vrk lyhyempi kuin keski-ikäisillä lehmillä. KNotrin mukaan lisäksi vanhoilla lehmillä tiineysaika on jossain määrin lyhyempi kuin keski-ikäisillä lehmillä. Koska vanhemmat lehmät ovat yleensä kookkaampia kuin nuoret, voisi ajatella, että edellä mainittu iän vaikutus tiineysajan pituuteen perustuisi vanhempien lehmien suurempaan kokoon nuoriin verrattuna. Penu-Lehtosen (l. c.) mukaan lehmän paino ei kuitenkaan vaikuta tiineysajan pituuteen. Todennäköisesti iän vaikutus tiineysajan pituuteen perustuu muutoksiin hormonaalisessa konstitutiossa lehmän vanhetessa.

Ilmeisesti ruokinnalla ja hoidolla on huomattava vaikutus tiineysajan pituuteen. Näitten tekijöitten vaikutuksesta tiineysajan pituuteen näyttää kuitenkin kirjallisuudessa olevan melko niukalti tietoja. PehU-Lehtosen (l. c.) aineistossa Jokioisten Ayrshire-karjoissa tiineysaika oli keskimäärin noin 2 vrk lyhyempi kuin yleensä Suomen Ayrshirekarjoissa. Pehu-Lehtonen arvelee tämän johtuvan pääasiassa paremmasta ruokinnasta ja hoidosta Jokioisten kartanoissa kuin yleensä muualla maassa. JAKUBEC (8, pp. $270-271$ ) ei saattanut todeta vuorosuhdetta tiineysajan ja ummessaoloajan pituuden välillä.

Puhtaista ympäristötekijöistä näyttää sillä vuodenajalla, jolloin poikiminen tapahtuu, olevan melkoinen vaikutus tiineysajan pituuteen. BRAKEL et al. (l. c.) ovat useilla roduilla Ohio-valtiossa Yhdysvalloissa todenneet, että kevätkuukausina poikivien lehmien tiineysaika oli keskimäärin 2.07 vrk pitempi kuin syyskuukausina poikivien lehmien. JoHANssonin (l.c.) mukaan tiineysajan pituus näytti olevan riippuvainen vuodenajasta sit€n, että ne tiineysajat, joiden jälkimmäinen puolisko sattui talvikuukausille, olivat keskimäärin $1-2$ vrk pitempiä kuin ne, joiden vastaava aika sattui kesäkuukausille. Pehu-Lehtosen (l. c.) mukaan joulu-helmikuussa poikivilla lehmillä tiineysaika on keskimäärin $2-3$ vrk pitempi kuin touko- 
elokuussa poikivilla. Tiineysaika näyttää siis talvella ja keväällä poikivilla lehmillä olevan jonkinverran pitempi kuin kesällä ja syksyllä poikivilla lehınillä.

Kysymykseen tiineysajan pituudesta naudalla liittyy läheisesti kysymys vasikan painoon vaikuttavista tekijöistä. BuRrisin ja BLunvin (4, pp. 395-396) Angus-, Hereford- ja Shorthorn-roduista keräämän aineiston perusteella voidaan laskea, että vasikan paino eri roduilla kasvaa keskimäärin noin 0.4 kg, kun tiineysaika pitenee yhdellä vuorokaudella. PeHu-Lehtonen (13, p. 64) on saanut 2851 tiineystapauksen perusteella Ayrshire-karjoissa vasikan painon ja tiineysajan väliseksi vuorosuhteeksi $\mathrm{r}=+0.387 \pm 0.0159$. Kaksostapauksissa on vasikan painoksi otettu vasikkain yhteispaino. Vasikan painon $(\mathrm{y})$ ja tiineysajan pituuden $(\mathrm{x})$ välisen regressiokertoimen arvo oli $\mathrm{R} \frac{\mathrm{y}}{\mathrm{x}}=0.11 \mathrm{~kg} / \mathrm{p}$. KRIžEnECKy ja KuDLičkA (11, pp. 299-320) ovat suureen böömiläisistä ja määriläisistä paikallisroduista kerättyyn aineistoon perustuen todenneet, että emän painon kasvaessa vasikan todellinen paino kasvoi, mutta suhteellinen paino (prosentteja emän painosta) sensijaan pieneni. Lehmän iällä ei ollut lainkaan vaikutusta, ummessaoloajan pituudella sensijaan heikko positiivinen vaikutus vasikan painoon. FITCH et al. (6, p. 196) ovat todenneet, että emän ruokinta vaikuttaa vasikoiden syntymäpainoon vain silloin, kun ruokinta pitemmän ajan on niukka.

\section{Tiineysajan pituus Viikin koetilan karjassa}

Tutkimusta varten koottu aineisto on peräisin Viikin opetus- ja koetilan Ayrshire-karjaa koskevasta kirjanpidosta. Primääriaineistoksi on kerätty seuraavat tiedot: 1) astutuspäivämäärät, 2) poikimispäivämäärät, 3) poikimiskerran järjestysluku, 4) lehmän paino ja kuntoluokka (lihavuusaste) kolme päivää poikimisen jälkeen, 5) vasikan sukupuoli ja paino, 6) kerrallaan syntyneiden vasikoiden lukumäärä. Aineistoon on otettu mukaan aikajärjestyksessä kaikki tiineystapaukset Viikin Ayrshire-karjan perustamisesta lähtien (1946), paitsi sellaiset, joissa vasikka on syntynyt kuolleena. Kertynyt aineisto käsittää yhteensä 382 tiineystapausta. Aineiston matemaattinen käsittely on suoritettu KronAcherin (12, pp. 1-71), eräitä kohtia myös BoNnIER-TEDinin (2, pp. 139-146) esittämällä tavalla.

Tiineysajan pituuden jakaantumista aineiston yksittäisvasikkatapauksissa kuvaa taulukko 2. Tiineysaikojen pituuden keskiarvo oli $279.92 \pm 0.222$ vrk.

Té ulukko 2. Tiineysajan pituuden jakaantumistaulu.

\begin{tabular}{|c|c|c|c|c|c|c|c|c|c|c|c|c|c|c|c|c|}
\hline $\begin{array}{l}\text { Tiineys- } \\
\text { päivien } \\
\text { luku }\end{array}$ & $\begin{array}{l}265- \\
266\end{array}$ & $\begin{array}{l}267- \\
268\end{array}$ & $\begin{array}{l}269 \\
270\end{array}$ & $\begin{array}{l}271- \\
272\end{array}$ & $\begin{array}{l}273- \\
274\end{array}$ & $\begin{array}{l}275- \\
276\end{array}$ & $\begin{array}{l}277- \\
278\end{array}$ & $\begin{array}{l}279- \\
280\end{array}$ & $\begin{array}{l}281- \\
282\end{array}$ & $\begin{array}{l}283- \\
284\end{array}$ & $\begin{array}{l}285- \\
286\end{array}$ & $\begin{array}{l}287- \\
288\end{array}$ & $\begin{array}{l}289- \\
290\end{array}$ & $\begin{array}{l}291- \\
292\end{array}$ & $\begin{array}{l}293- \\
294\end{array}$ & $\begin{array}{l}\text { Yh- } \\
\text { teensä }\end{array}$ \\
\hline $\begin{array}{c}\text { Tapausten } \\
\text { luku }\end{array}$ & 2 & 1 & 2 & 6 & 30 & 35 & 64 & 64 & 64 & 59 & 26 & 14 & 6 & 1 & 1 & 375 \\
\hline
\end{tabular}


Hajonnan arvo oli 4.30 vrk ja muuntelukertoimen $1.54 \%$. Hajonta oli siis suhteellisen vähäinen. Tïneysaika vaihteli 76 prosentilla lehmistä $275-284$ vrk ja 98 prosentilla $270-290 \mathrm{vrk}$. Lyhin tiineysaika oli 265 vrk ja pisin 293 vrk.

Primääriaineistossa oli 7 sellaista kaksosvasikkatapausta, joissa molemmat vasikat olivat syntyneet elävinä. Tiineysajan pituuden keskiarvo oli näissä tapauksissa $273.14 \pm 1.224$ vrk eli $6.78 \pm 1.24$ vrk lyhyempi kuin tapauksissa, joissa syntyi vain yksi vasikka. Lyhin tiineysaika kaksosvasikkatapauksissa oli 269 vrk ja pisin 277 vrk.

Aineistossa oli 191 tiineystapausta, joissa syntyi yksi lehmävasikka ja 184 tapausta, joissa syntyi yksi sonnivasikka. Tiineysajan pituuden keskiarvo oli lehmävasikkatapauksissa $279.51 \pm 0.316$ vrk ja sonnivasikkatapauksissa $280.32 \pm 0.312$ vrk. Sonnivasikoiden sikiökausi oli keskimäärin $0.81 \pm 0.45$ vrk pitempi kuin lehmävasikoiden.

Ensikantoisia lehmiä oli tilastossa 75 eli noin $20 \%$ koko aineistosta. Tiineysajan pituuden keskiarvo oli näillä $279.53 \pm 0.538$ vrk. Koko aineiston (ilman kaksosvasikkatapauksia) lehmien ja ensikantoisten lehmien tiineysaikojen keskiarvojen erotus oli $0.39 \pm 0.58 \mathrm{vrk}$, mikä erotus ei ole tilastollisesti merkitsevä.

Viikin koetilalla on vuodesta 1949 lähtien jokainen lehmä punnittu kolmantena päivänä poikimisen jälkeen, $3 \mathrm{kk}$ poikimisen jälkeen ja $6 \mathrm{kk}$ poikimisen jälkeen. Näiden punnitusten ohella on lehmät silmämääräisesti luokiteltu lihavuusluokkiin. (Arvostelun tukena on kipsiin valetut tyyppimallit eri lihavuusluokista.) Luokkia on 7. Luokkaan I tulevat erittäin lihavat lehmät ja luokkaan VII erittäin laihat. Luokka IV kuuluu keskilihaville. Ottamalla huomioon rinnakkaiset punnitustulokset ja lihavuusaste-arvioinnit on ollut mahdollista kehittää laskutapa, jolla lehmien painot on muunnettu normaalipainoiksi eli neljättä lihavuusluokkaa vastaaviksi painoiksi. Tällöin on otettu huomioon vain vähintään 3 kertaa poikineet lehmät. Täten kertynyt tilasto on tehnyt mahdolliseksi tarkastella tiineysajan pituuden ja lehmän normaalipainon välistä vuorosuhdetta. Tähän tarkasteluun on valittu ne yksittäisvasikkatapaukset, joissa vasikka on syntynyt kolmannen tai sitä myöhemmän tiineyskauden jälkeen. Näitä tapauksia on ollut kaikkiaan 136 . Vuorosuhdekertoimen arvoksi saatiin $\mathrm{r}=-0.051 \pm 0.086$, mistä päättäen tiineysajan pituus näyttää olevan riippumaton eläimen normaalipainosta.

Lehmän lihavuusasteen vaikutusta tiineysajan pituuteen on tutkittu vertaamalla keskenään toisessa ja neljännessä lihavuusluokassa olevien lehmien tiineysajan pituuksia. Toisessa lihavuusluokassa olevien lehmien tiineystapauksia oli yhteensä 97 ja neljännessä 67 . Toisessa luokassa olevien lehmien tiineysaika oli keskimäärin $0.70 \pm 0.680$ vrk pitempi kuin neljännessä luokassa olevien lehmien. Lehmän lihavuusaste ei tämän tarkastelun perusteella siis näytä sanottavasti vaikuttaneen tiineysajan pituuteen. Mahdollista kuitenkin on, että jos vertailtavien lehmäryhmien välillä olisi ollut suurempi lihavuusaste-ero, tarkastelun tulos olisi muodostunut toisenlaiseksi. Viikin lehmäaineistosta ei kuitenkaan ollut löydettävissä heikompien lihavuusluokkien kohdalta riittävän suurta yksilöryhmää. 
Taulukko 3. Vasikan painon (y) ja tiineysajan pituuden (x) välinen riippuvaisuussuhde.

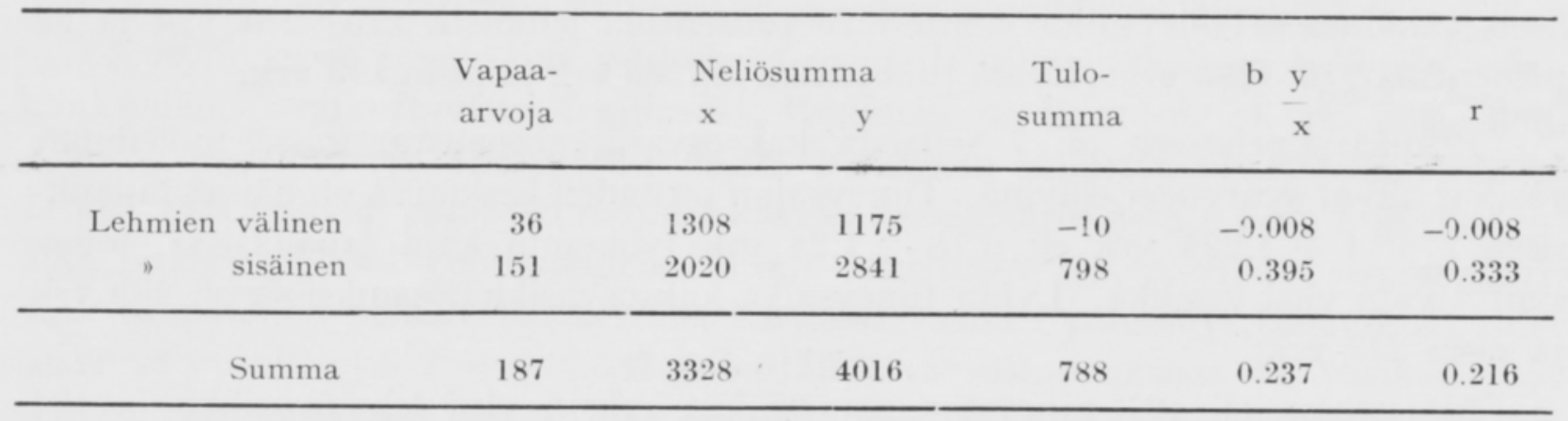

Aineistossa oli 348 tiineystapausta, joissa tunnettiin sekä tiineysajan pituus että vasikan paino. Vasikan painon (y) ja tiineysajan pituuden $(\mathrm{x})$ väliseksi vuorosuhdekertoimeksi saatiin $\mathrm{r}=+0.146 \pm 0.052$ ja regressiokertoimeksi $\mathrm{R} \frac{\mathrm{y}}{\mathrm{x}}=0.162 \pm$ $0.061 \mathrm{~kg} / \mathrm{p}$ ja regressiokertoimeksi $\mathrm{R} \frac{\mathrm{x}}{\mathrm{y}}=0.132 \pm 0.050 \mathrm{p} / \mathrm{kg}$. Vuorosuhde on siis melko vähäinen.

Tiineysajan pituuden ja vasikan painon välinen vuorosuhde selvitettiin myös laskemalla ns. lehmien sisäiset vuorosuhde- ja regressiokertoimet BonniER-TEDINin (2, pp. 139-146) esittämällä tavalla. Aineistoon kuuluivat ne lehmät, jotka olivat poikineet neljä kertaa tai sitä useammin. Tällaisia lehmiä oli kaikkiaan 37, ja tiinevstapausten luku 188. Tällaiset kertoimien arvot kuvaavat riippuvaisuussuhdetta lähinnä yksilöillä keskimäärin, kun sensijaan lehmien välinen taso eliminoituu. Tulokset ilmenevät taulukosta 3 . Vuorosuhde- ja regressiokertointen arvot ovat yli kaksi kertaa niin suuret kuin mitä edellä summa-aineiston perusteella saatiin.

Vasikan painon $(\mathrm{y})$ ja emän normaalipainon $(\mathrm{x})$ väliseksi vuorosuhteeksi saatiin 136 tiineystapauksen perusteella $\mathrm{r}=+0.113 \pm 0.085$. Vuorosuhteen arvo on siis varsin vähäinen ja tilastollisesti epävarma. Emän normaalipainon hajonnan arvo oli $46.18 \mathrm{~kg}$.

Poikimiskerran järjestysluvun vaikutusta vasikan painoon selvitettiin vertaamalla keskenään ensimmäistä ja neljättä kertaa poikivien lehmien vasikoiden painoja. Ensimmäistä kertaa poikivia lehmiä oli 75 ja näiden vasikoiden keskipaino $31.19 \pm 0.513 \mathrm{~kg}$. Neljättä kertaa poikivia lehmiä oli 49 ja näiden vasikoiden keskipaino $34.16 \pm 0.329 \mathrm{~kg}$. Neljättä kertaa poikivien lehmien vasikat olivat keskimäärin $2.98 \pm 0.609 \mathrm{~kg}$ painavampia kuin ensimmäistä kertaa poikivien lehmien vasikat. Neljättä kertaa poikivien lehmien keskimääräinen normaalipaino oli 81.6 kg suurempi kuin ensi kertaa poikivien. Edellisessä kappaleessa esitetyn perusteella voitaneen päätellä, että kysymyksessä olevien vasikkaryhmien keskipainojen eroavuus ei ole määräytynyt ainakaan pääasiassa emien normaalipainojen eroavuudesta. Mahdollisesti tässä on kysymys lehmien hormonaalisen konstitution muuttumisesta iän karttuessa.

Aineistossa oli 174 lehmävasikkaa, joiden keskipaino oli $32.34 \pm 0.311 \mathrm{~kg}$ ja samoin 174 sonnivasikkaa, joiden keskipaino oli $34.56 \pm 0.386 \mathrm{~kg}$. Sonnivasikoiden paino oli keskimäärin $2.22 \pm 0.495 \mathrm{~kg}$ suurempi kuin lehmävasikoiden. 


\section{Yhteenveto}

Tiineysajan pituutta ja siihen vaikuttavia tekijöitä on tutkittu Viikin opetusja koetilan Ayrshire-karjaa koskevan kirjanpidon perusteella. Aineistoon kuului 382 sellaista tiineystapausta, joissa vasikka syntyi elävänä. Tällöin päädyttiin seuraaviin tuloksiin:

1. Tiineysajan pituuden keskiarvo ilman kaksosvasikkatapauksia oli $279.92 \pm$ 0.222 vuorokautta, hajonta 4.30 vuorokautta ja muuntelukerroin $1.54 \%$. Tiineysajan pituus vaihteli 265 - 293 vuorokauteen.

2. Kaksosvasikkatapauksissa tiineysajan pituus oli $6.78 \pm 1.24$ vuorokautta lyhyempi kuin silloin, kun syntyi ainoastaan yksi vasikka.

3. Sonnivasikoiden sikiökausi oli keskimäärin $0.81 \pm 0.45$ vuorokautta pitempi kuin lehmävasikoiden.

4. Ensikantoisten lehmien tiineysajan pituus ei ollut mainittavasti lyhyempi kuin vanhempien lehmien.

5. Tiineysajan pituuden ja lehmän normaalipainon välillä ei havaittu riippuvaisuussuhdetta. Samoin tiineysajan pituus ei ainakaan huomattavasti ollut riippuvainen lehmän lihavuusasteesta.

6. Tiineysajan pituuden ja vasikan painon väliseksi vuorosuhdekertoimeksi saatiin $\mathrm{r}=+0.146 \pm 0.052$ koko aineiston perusteella. Vastaavan lehmien sisäisen vuorosuhteen arvo oli $\mathrm{r}=+0.333$ ja regressiokertoimen arvo $\mathrm{R}_{\mathrm{x}}^{\mathrm{y}}=0.395$ $\mathrm{kg} / \mathrm{vrk}$.

7. Vasikan painon $(\mathrm{y})$ ja lehmän normaalipainon $(\mathrm{x})$ välinen vuorosuhde oli $\mathrm{r}=+0.113 \pm 0.085$. Ensimmäistä kertaa poikineiden lehmien vasikoiden paino oli keskimäärin $2.98 \pm 0.609 \mathrm{~kg}$ pienempi kuin neljättä kertaa poikineiden. Sonnivasikoiden keskipaino oli $2.22 \pm 0.495 \mathrm{~kg}$ suurempi kuin lehmävasikoiden.

Tutkittaessa tiineysajan pituutta ja siihen vaikuttavia tekijöitä on päädytty yleensä samanlaisiin tuloksiin kuin ne, joita kirjallisuuskatsauksessa on esitetty. Ensikantoisten lehmien tiineysaika ei kuitenkaan ollut merkitsevästi lyhyempi kuin vanhempien lehmien niinkuin kirjallisuuskatsauksessa mainituissa tapauksissa oli. Lehmän lihavuusasteen vaikutusta tiineysajar pituuteen tiettävästi ei aikaisemmin ole tutkittu.

(1) Axelsson, J. 1931. Die Dauer der Trächtigkeit des Rindes. Jb. für Tierzucht 23.

(2) Bonnier-Tedin 1940. Biologisk variationsanalys. Stockholm.

(3) Brakel, W. J. \& Rice, D. C. \& Salisbury, S. M. 1952. Factors associated with the duration of gestation in dairy cattle. J. Dairy Sci. 35.

(4) Burris, J. M. \& Blunn, C. T. 1952. Einige Faktoren, die die Trächtigkeitsdauer und das Geburtsgewicht von Fleischrindern beeinflussen. Z. für Tierzüchtung und Züchtungsbiologie 60 .

(5) Copeland, L. 1931. Trächtigkeitsdauer bei Jersey-kühen. Züchtungskunde VI. 
(6) Fitch, J. B. \& Mc Gilliard, P. C. \& Drumm, G. M. 1925. Untersuchungen über das Geburtsgewicht und die Trächtigkeitsdauer von Milchvieh. Z. für Tierzüchtung und Züchtungsbiologie IV

(7) Fraser, H. A. 1940. Jb. für Tierzucht 31.

(8) JaKubec, Vaclav 1943. Einige die Variabilität der Trächtigkeitsdauer beim Rind beeinflussende Faktoren. Z. für Tierzüchtung und Züchtungsbiologie 54 .

(9) Johansson, I. 1929. Die Länge der Tragezeit bei Rindern und Schweinen. Züchtungskunde IV.

(10) Клотт, J. C. 1932. A study of the gestation period of Holstein-Friesian cows. J. Dairy Sci. 15.

(11) KrižEnecky, J. \& KudličKa, K. 1944. Úber den Einfluss der Dauer der Trockenzeit auf das Gewicht des neugeborenen Kalves. Z. für Tierzüchtung und Züchtungsbiologie 56.

(12) Kronacher, C. 1930. Biometrik. Berlin.

(13) Pehu-Lehtonen, M. 1933. Lehmän tiineysajan pituudesta ja siihen vaikuttavista tekijöistä. Yliopistollinen laudaturkirjoitus.

(14) Pusch, G. 1911. Lehrbuch der Allgemeinen Tierzucht. Stuttgart.

(15) Sabatini, P. 1908. Untersuchungen über die Dauer der Tragezeit bei unseren wichtigsten Haustieren. Jb. für wiss. und praktische Tierzucht III.

(16) Samjatin, N. M. 1933. Das Geschlecht, die Länge der Trächtigkeitsdauer und das Lebensgewicht der neugeborenen Kälber des Kirgisischen Rindes. Züchtungskunde VIII.

(17) Spann, J. 1943. Fälle von verlängerter Tragezeit beim Rind und von nachgeborenen Föten. Tierzüchtung 54 .

(18) Werner, H. 1902. Die Rinderzucht. Berlin.

\section{S U M M A R Y :}

\section{DURATION OF GESTATION IN THE AYRSHIRE CATTIE ON HE VIIK EXPER MENT.I, FARM}

Aarne Mäkelä and Raija Oittilla

\section{Department of Animal Husbandry, University of Helsinki}

The duration of gestation of the Ayrshire cattle on the University Educational and Experimental Farm has been studied on the ground of a special bookkeeping held on the farm. The material consisted of 382 gestations in which the calves were born alive. The following results were obtained:

1. The duration of gestation, excluding twin gestations, averaged $279.92 \pm 0.222$ days, the standard deviation being 4.30 days and the coefficient of variation 1.54 per cent. The range of these gestations was $265-293$ days.

2. Gestations in which twins were born were on an average $6.78 \pm 1.24$ days shorter than when only one calf was born.

3. Male calves were carried on an average $0.81 \pm 0.45$ days longer than female calves.

4. The first gestations were not significantly shorter than later gestations.

5. The normal weight of the dam ${ }^{1}$ had no effect upon gestation length when only the $3 \mathrm{rd}$ and later gestations were considered. Furthermore the length of gestation showed little, if any, correlation with the degree of fatness of the cow.

6. The correlation between gestation length and birth weight of the calf was $r=+0.146 \pm 0.052$ when calculated for the whole material. The corresponding coefficient within cows was $r=+0.333$ and regression coefficient $\mathrm{R}_{\mathrm{x}}^{\mathrm{y}}=0.395 \mathrm{~kg} /$ day.

7. The correlation between the birth weight of the calf $(\mathrm{y})$ and the normal weight of the dam $(\mathrm{x})$ was $r=+0.133 \pm 0.085$. The average weight of the calves of cows calving for the first time was $2.98 \pm$ $0.609 \mathrm{~kg}$. smaller than that of cows calving the fourth time. Male calves weighed on an average 2.22 $\pm 0.495 \mathrm{~kg}$. more than female calves.

1 The influence of the degree of fatness was eliminated. 